2006

\title{
A Truancy Court Program to Keep Students in School
}

Barbara A. Babb

University of Baltimore School of Law, bbabb@ubalt.edu

Follow this and additional works at: http://scholarworks.law.ubalt.edu/all_fac

Part of the Criminal Law Commons, Education Law Commons, Family Law Commons, and the Juvenile Law Commons

\section{Recommended Citation}

A Truancy Court Program to Keep Students in School, 39 Md. B.J. 45 (2006)

This Article is brought to you for free and open access by the Faculty Scholarship at ScholarWorks@University of Baltimore School of Law. It has been accepted for inclusion in All Faculty Scholarship by an authorized administrator of ScholarWorks@University of Baltimore School of Law. For more information, please contact snolan@ubalt.edu. 


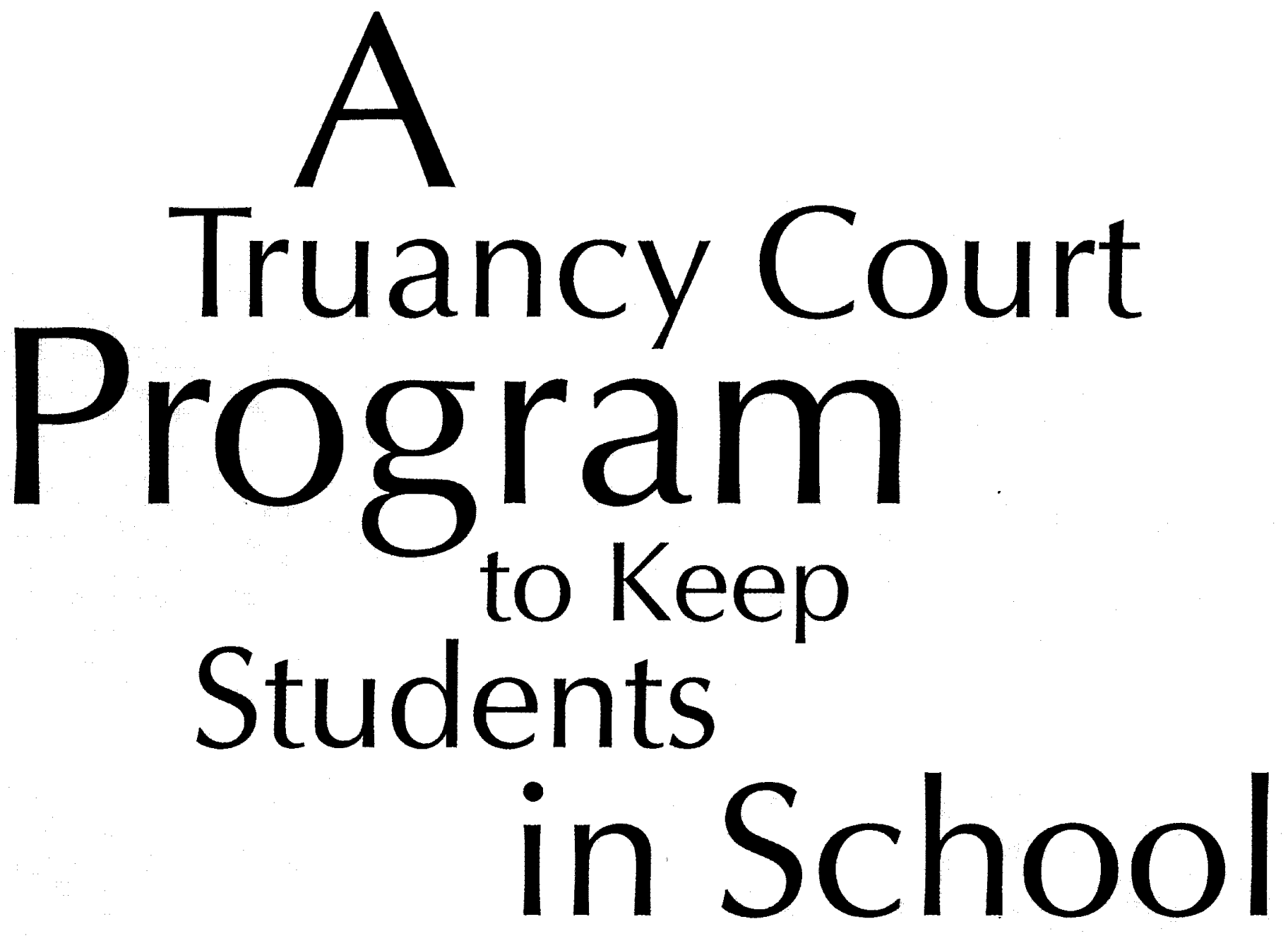

nder Maryland law, "[e]ach person who has legal custody or
care and control of a child who is 5 years old or older and
under 16 shall see that the child attends school...." MD. Education Code Ann. $\$ 7-301$ (c) 2006. The law also provides penalties for violations, as the legal custodian or caregiver "who fails to see that the child attends school...is guilty of a misdemeanor," which could result in fines of $\$ 50$ to $\$ 100$ per day of unlawful absence and/or imprisonment for 10 to 30 days, depending upon whether the conviction is a first or subsequent conviction. MD. Education Code Ann. § 7103(e)(2)(i)(ii). 
Despite this legal imperative, however, the Baltimore City Public School System, which defines truancy as more than twenty days of unexcused absences, grapples with a truancy rate that consistently hovers around thirty percent. (Tom Pelton, City to Launch Anti-Truancy Effort, Balt. Sun, Aug. 14, 2003, at 3B.) This means that on any given day in Baltimore City, around 6000 of the system's nearly 90,000 students are truant.

Why is it important for a community to care about truancy rates, in comparison to more compelling issues, such as substance abuse and crime? High rates of truancy are linked to high daytime vandalism and burglary rates. Ramona Gonzales, Kinette Richards \& Ken Seeley, Youth Out of School: Linking Absence to Delinquency, Colo. Found. for Fam. and Child. Sept. 2002, at 3 [here- inafter Gonzales]. The cyclical nature of truancy, meaning the more truant a child becomes, the more humiliating and futile school attendance becomes for the child, results in an increasingly greater reluctance to return to school.

Further, research has demonstrated that truancy is an early indicator of more serious potential delinquent behavior, social isolation, substance abuse, teen pregnancy, educational failure, and school dropout. Allison J. Bell, Truancy Intervention, $57 \mathrm{~J}$. of Res. Dev.in Educ. 203-11, 1994. These outcomes inhibit youth from becoming productive citizens and are links to problems in adulthood, such as violence, marital difficulties, employment issues, adult criminality, and incarceration. See Gonzales, supra, at 4.

The Center for Families, Children and the Courts (CFCC) at the University of Baltimore School of Law has

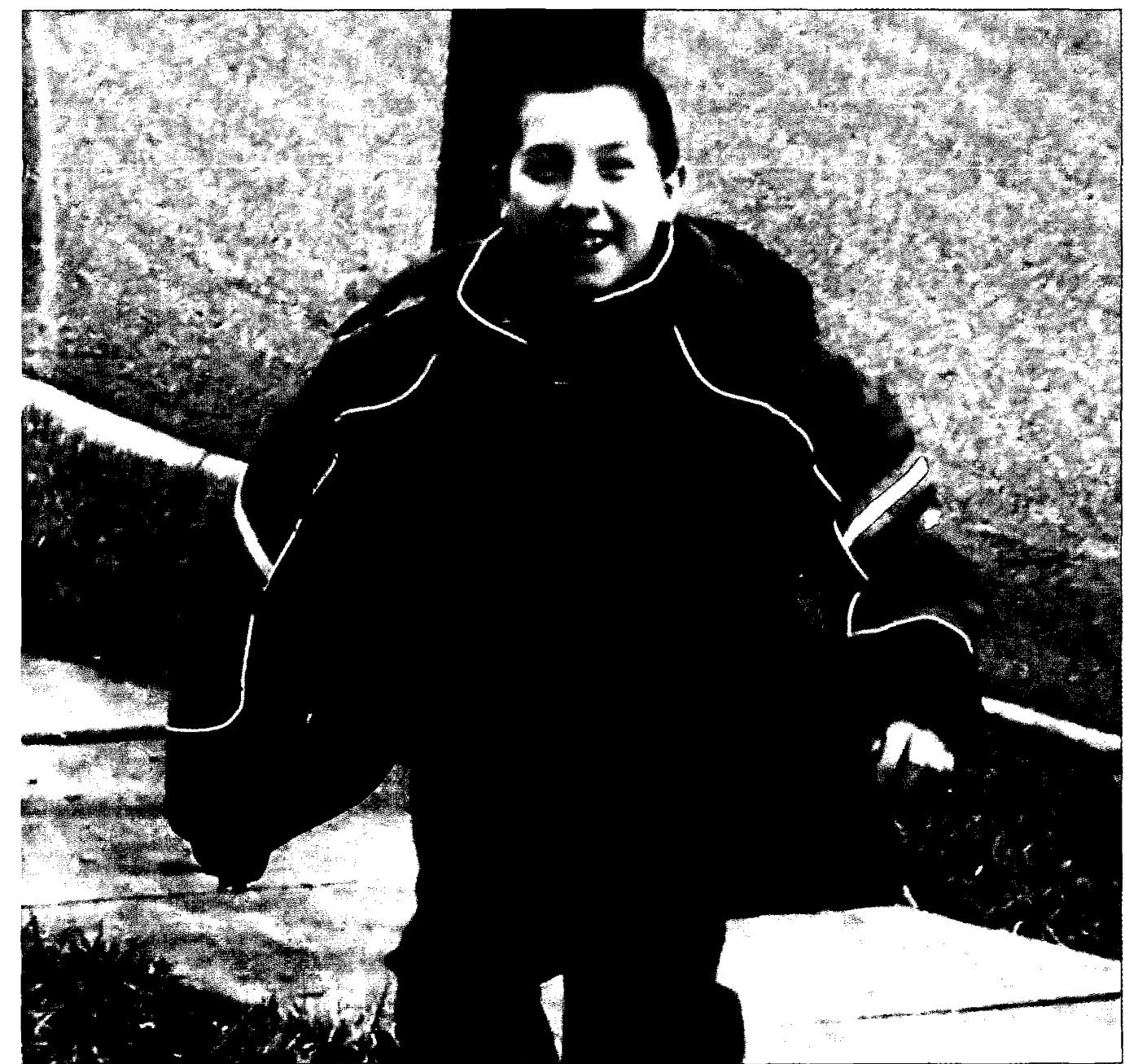

devoted substantial time and effort to provide one means to address truancy and to reverse the cycle of truant behavior. With funding from the Charles Crane Family Foundation, CFCC has created a Truancy Court Program (TCP) now in operation in five Baltimore City elementary and middle schools.

CFCC's mission is to create, foster and support a national movement to integrate communities, families, and the justice system in order to improve the lives of families and the health of the community. CFCC undertakes projects from the perspectives of therapeutic jurisprudence, or the ability of the law to intervene in a helpful manner to improve the lives of families and children, and the ecology of human development, or a holistic approach that explores and accounts for the interrelationships among children and families and the many systems affecting their lives.

From this orientation, CFCC aims to link legal and social science research and scholarship to real world problems in an effort to effectuate change. Further, in keeping with the institutional vision of the University of Baltimore, CFCC attempts to develop creative solutions to urban challenges. CFCC accomplishes its work by cultivating relationships among diverse stakeholders representing as many systems as feasible and by formulating a strategy based upon the input of the stakeholders. With this orientation as its focus, CFCC set out to design an approach to truancy that aims to avoid the criminal perspective and consequences of existing Maryland law.

To develop its Truancy Court Program, the only program of its kind emanating from a law school, the University of Baltimore's CFCC has partnered with the Baltimore City District and Circuit Court judges, the Office of 
the Mayor of Baltimore City, and the Baltimore City Public School System. In addition to these "official" partners, CFCC has convened several stakeholder meetings to gather input about and suggestions for the structure and operation of the program. These meetings have included representatives from the Baltimore City Council, Office of the State's Attorney, Office of the Public Defender, Department of Social Services, and Family League, as well as the Maryland Administrative Office of the Courts and Department of Juvenile Services.

A fundamental principle to the TCP design is that by addressing truancy early and often throughout the child's education, there is a far greater likelihood of effective intervention into both truancy and related problems. In addition, under CFCC's model, parents or caregivers must participate in the Truancy Court Program, which is a non-adversarial approach geared to "soft" truants, or those students who have less than twenty days of unexcused absences and who are likely to still have academic, social, and emotional connections to the school. Finally, recognizing that truancy does not exist in a vacuum, CFCC's program aims to identify the root causes of truancy, such as problems in the child's home, and to provide the necessary services to children and their families to alleviate the impediments, a nonpunitive approach to truancy.

The Truancy Court Program operates within the confines of the public school, rather than in a courtroom. Nonetheless, the program capitalizes on the stature and authority of a judge, who has no legal authority but whose physical presence and moral authority are compelling. After the schools select students to participate in the Truancy Court Program, they send letters to parents or caregivers describing the program, requesting permission for the child to participate, and addressing the requirement that they, too, must be involved.

Each Truancy Court Program runs for approximately eight to ten weeks and is strictly voluntary on the part of the student and the parent or caregiver. The weekly in-school sessions involve a judge, a team of school representatives, the child, and the child's parent or caregiver. The school team may consist of a family advocate, the school attendance clerk, a counselor, a school psychologist, a school social worker, and/or an educational liaison, who is often a teacher representing the academic connection between program participants and school staff.

At the school, the judge or master, who volunteers his or her time, reviews each child's file prior to meeting one-on-one with the child and parent/caregiver. The judge then engages the family in conversation, reviews and discusses the child's attendance record for the week, and asks questions about any problems.

The judge's main role is to positively reinforce progress or to elicit reasons why the child has failed to attend school. Specific goals are established which the child aims to accomplish by the next session, and each week the child is rewarded with a small gift.

As Baltimore Sun columnist Dan Rodricks has written after his observation of a Truancy Court Program session, "So here's ... a judge giving up her time-before a busy family court docket downtown-to try to apply a little pressure on adults so that a child has a chance in life. This is the kind of intimate, direct intervention so badly needed among the children of the poor and dysfunctional...." Dan Rodricks, Effort Aims to Fix Lives, One Child at a Time," Balt. Sun, May 19, 2005, at 1B.
Interventions the judge may order include tutoring, written assignments, outreach to various social services, special education screening, and mentoring, among others. Efforts also are made to support parents experiencing difficulties, such as poor organizational skills, that impede their ability to get children to school.

The Truancy Court Program currently operates in two elementary schools, Holabird and Elmer Henderson, and three middle schools, Canton, Highlandtown, and Southeast. As of January, 2006, two Truancy Court Program sessions have concluded at each school, with two additional sessions per school slated to operate before the school year concludes.

The specific goals of the Truancy Court Program are as follows: 1) Lower truancy rates in Baltimore City. 2) Improve school performance by participating students.

Decrease daytime juvenile crime rates in the neighborhoods surrounding the schools. 4) Increase parental/caregiver involvement in the child's education. 5) Expand the range of social services offered to students and their families.

In addition to the project's goals, the students can benefit in several ways: 1) School performance should improve, both academically and socially. 2) Students can feel a greater sense of belonging in the school and surrounding community. 3) Students gain stronger ties to their families as a result of the families' participation in the program. 4) Students can receive necessary services, such as tutoring, to maximize their potential for academic success.

Public school students are not the only students involved in the TCP. University of Baltimore law students enrolled in the CFCC Student Fellows Program, a law school course 
designed to promote an understanding of court reform in family law and an interdisciplinary approach to family law problem-solving, play a pivotal role in the TCP. The CFCC Student Fellows Program is an example of how the School of Law aims to link theory with practice.

To fulfill the requirements of an experiential component designed to accompany the theoretical aspect of the CFCC Student Fellows Program, law students act as the liaisons among the TCP schools, the judges, and CFCC. Each student fellow is responsible for the overall operation of the TCP in a particular school, including attending the weekly TCP meetings, assuring that attendance data is available for the judge, assisting the judge with the processing and monitoring of each student, and helping to link students and their families with needed services.

How have the law students reacted to the TCP, given their "hands on" experience? According to one CFCC student fellow, "[y]ou never really realize that there are so many problems that contribute to a child not attending school until you sit in on a [TCP] session. Going to school can be difficult when approached with pressure to join gangs, not comprehending class work that classmates seem to have no difficulty with, or not waking up on time because a parent or alarm clock is unavailable in the mornings.

Children and their parents bring up reasons which contribute to truancy that I never fathomed." Unpublished student paper, Univ. Balt. School of Law, on file with author. Another CFCC student fellow has summarized his experiences with the TCP. "I am so pleased to have been able to participate in the Truancy Court Program. It is inspirational and invigorating to know that there are individuals and groups that care about adolescent education. A program that makes a difference in at least one student's situation is worth more than I can communicate." Unpublished student paper, Univ. Balt. School of Law, on file with author.

In fact, the law students' enthusiasm for the TCP prompted CFCC faculty to launch a university-wide volunteer initiative. A presentation about the TCP open to the entire University of Baltimore community has garnered support from over forty individuals. The schools have received the volunteers' contact information, and they have engaged the volunteers to tutor, read to classes, mentor, provide rewards or incentives, and assist with standardized test taking, among other activities. CFCC hopes to expand the $\mathrm{TCP}$ volunteer initiative during the final two sessions.

Anecdotal comments aside, how are the TCP students actually faring? Does the TCP make a difference? Preliminary data gathered after the first TCP session ending last June indicate dramatic results. The most striking results emerge from the two elementary schools, where the number of absences and tardies during and after the TCP declined precipitously from those prior to the TCPfrom a high of 58 prior to the program for one student to a low of zero during and after the TCP for that same student.

Among the middle schools, the prior to, versus the during/after, comparisons are less striking, but the pattern appears the same. In general, during and after the TCP, absences and tardies have declined markedly. CFCC has gathered data for the TCP session that recently has concluded, although that data has not been analyzed to date. CFCC also plans to gather data for the remaining two sessions and to publish comprehensive results of its findings.

In addition to the statistical data, what lessons have TCP organizers learned thus far? As one CFCC student fellow has reflected, "there is no 'one size fits all' about truancy." Unpublished student paper, Univ. Balt. School of Law, on file with author. Indeed, root causes underlying truant behavior are myriad. Nonetheless, as CFCC student fellows and project organizers have observed, many parents and caregivers are desperately seeking help to reverse the cycle of truancy; unfortunately, they often do not know where to start.

Many times, truancy is symptomatic of a serious individual or family problem for which services are needed and, hopefully, are available. Enhancing communication between the schools and the home is critical. Students' participation in the TCP improves when there is consistent, meaningful communication between the school and the parents or caregivers.

Finally, while the TCP can assist children to improve their school attendance, the children need more. For example, children need to sense a connection between attending school daily and future opportunities. CFCC has begun to address some of these challenges by working with certain TCP judges and other volunteers who are attempting, through structured mentoring programs, to provide the children with positive role models.

Where do we go from here? As a Baltimore Sun Editorial focusing on the TCP has noted at the launching of the TCP, "The UB-organized plan has a grant for the next two years; we hope organizers are working to secure funding for the future, and to extend it to other districts." Back to School, Editorial, Balt. Sun, Dec. 27, 2004 , at 12A. In fact, plans are underway to do just that. With additional 
funding, CFCC hopes to expand the program to ten Baltimore City schools. Given that the TCP serves an average of forty-five students per school for each year of operation, expanding the program promises to reach 450 additional students and their families.

CFCC also envisions creating a full-time Truancy Court Program Coordinator position, as this role presently is very part-time. Along with coordinating the actual truancy court sessions, the TCP Coordinator identifies speakers on topics of interest to parents and caregivers attending the TCP and does a great deal of community outreach. In fact, CFCC hopes to hire a social services/community outreach professional to develop and integrate counseling, mediation, and other social services into the TCP and to act as a liaison to the mental health and social services communities. CFCC intends to develop ongoing training sessions for school administrators, counselors, and teachers on effective means to address truancy.

CFCC has initiated efforts to partner with the business community and with policymakers to provide internships and/or employment for successful TCP "graduates," one means to show students the relationship between attending school and future life possibilities. To ensure that the TCP can be replicated and perhaps "institutionalized," CFCC plans to publish a manual, including forms, releases, sample letters, and other documents necessary to operate the TCP.

Is the TCP worth all the time, money, and effort devoted toward it? TCP Coordinator Patricia Schminke has summarized the truancy court graduation at Holabird Elementary School on June 1, 2005, a familiar scenario among all the participating schools. She writes:

Eight students, ranging from kindergarten through fourth grade, graduated from the Truancy Court Program this morning. Holabird's principal, Dr. Vera Bethune-Stewart, presented each student with a certificate of achievement, while Baltimore City Circuit Court Judge Althea Handy said a few words of praise and encouragement to each of the "graduates."

Mothers and / or grandmothers attended the ceremony and, according to Judge Handy, it was the first time she saw some of them smiling. Each child was asked whether he/she would continue to attend school every day, to which one and all responded affirmatively.
A touching moment occurred when one of the youngest students timidly approached Judge Handy to proudly whisper, "I did all my homework this week." Judge Handy gave him a big hug and congratulations. Unpublished paper, Univ. Balt. School of Law, on file with author.

It is stories like these that motivate the TCP participants to care and to be involved. The TCP is an example of how an effective community partnership can translate into a positive change agent. CFCC and the University of Baltimore plan to keep moving forward and to remain an integral part of the TCP team. The students in Baltimore City deserve it.

Barbara Babb may be reached at bbabb@ubalt.edu.

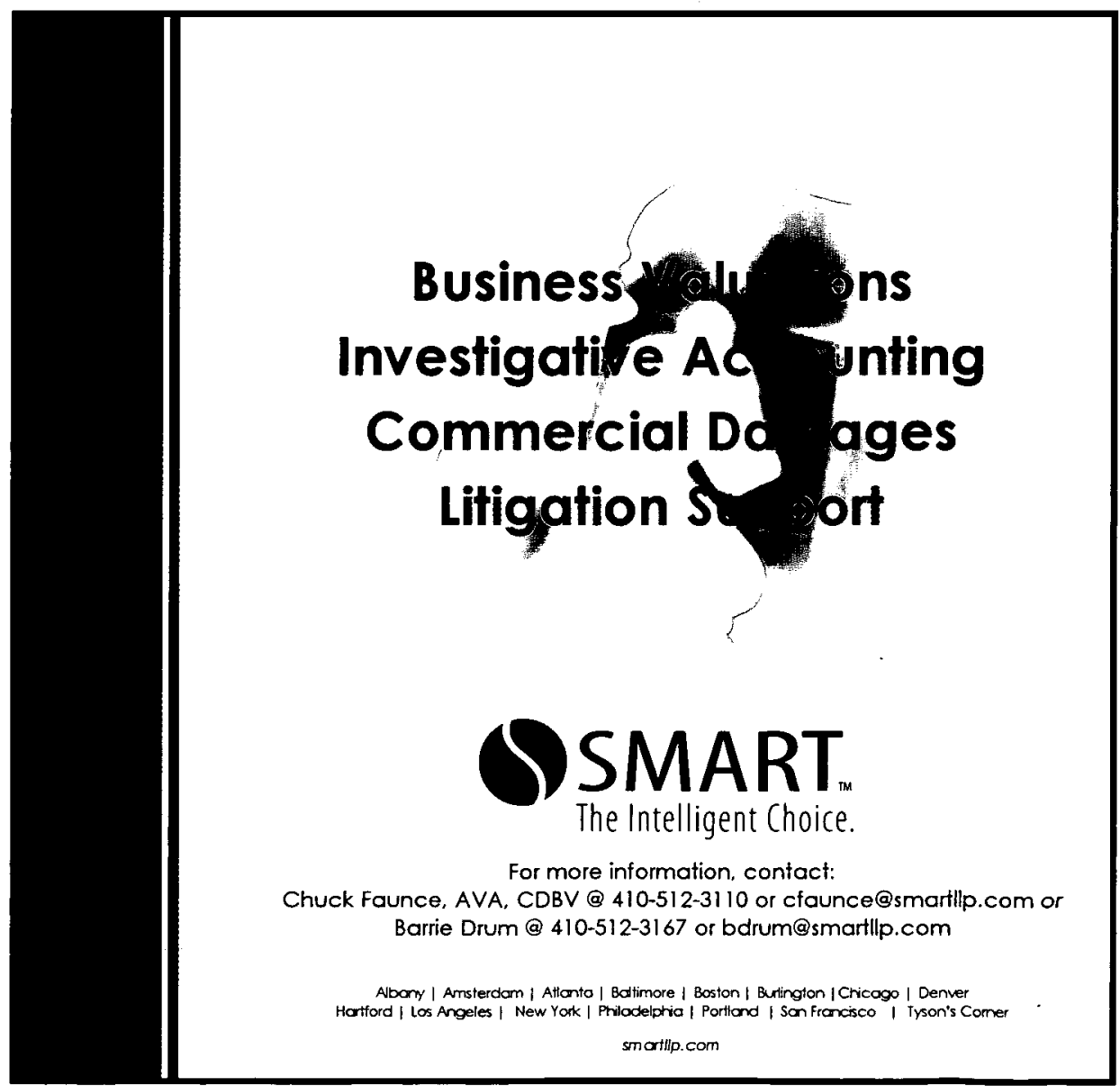

